Original Article

\title{
An electroencephalography (EEG) study of short-term electromyography (EMG) biofeedback training in patients with myofascial pain syndrome in the upper trapezius
}

\author{
Nattakarn Kaewcum, PT, PhD Candidate ${ }^{1)}$, Vorasith SiripornPanich, MD, PhD ${ }^{1 *}$ \\ 1) Research Center for Neuroscience, Institute of Molecular Biosciences, Mahidol University, Nakhon- \\ pathom 73170, Thailand
}

\begin{abstract}
Purpose] In the present study, electroencephalography was used to explore neural activity related to electromyography biofeedback training, focusing on pain perception before and after electromyography biofeedback. [Participants and Methods] Twenty-seven participants (female=23; mean age: $28.85 \pm 4.99$ years) with mild-to-moderate myofascial pain syndrome in the upper trapezius were recruited for this study. All participants underwent electroencephalography recording before, during, and after ( 0 and $15 \mathrm{~min}$ ) electromyography biofeedback training. Quantitative electroencephalography analysis was performed to obtain the absolute power of the four main frequency bands. Pain scores before and after electromyography biofeedback were also evaluated by subjective rating. [Results] Electromyography biofeedback increased alpha power and decreased delta power 15 minutes after training, suggestive of relaxation. However, although a tendency for scores to decrease was observed, no significant improvements in pain scores were observed following the intervention. Such results may be due to the short duration of the biofeedback session and the subjective nature of pain assessments. [Conclusion] Despite no obvious changes in pain perception, brief electromyography biofeedback training may induce relaxation in patients with myofascial pain syndrome of the upper trapezius muscle.

Key words: Biofeedback, EEG, Myofascial pain syndrome
\end{abstract}

(This article was submitted May 26, 2020, and was accepted Jul. 17, 2020)

\section{INTRODUCTION}

Chronic pain represents a major health problem in adolescent and adult populations ${ }^{1)}$, affecting $30-50 \%$ of people worldwide $^{2}$. Myofascial pain syndrome (MPS) is a chronic musculoskeletal disorder in which pain occurs due to a palpable spot in a taut band of muscle known as a trigger point ${ }^{3}$. MPS usually presents with deep, aching, and referred pain along the dermatome of innervating nerves in the muscle containing the trigger point. Additional symptoms such as weakness, limited range of motion, and alterations in autonomic nervous system (ANS) function have also been observed ${ }^{4,5)}$. MPS most commonly affects the trapezius muscle, especially the upper portion $(93.75 \%)$, followed by the levator scapulae $(82.14 \%)$, multifidus $(77.68 \%)$, and splenius cervicis muscles $(62.5 \%)^{6}$.

While several techniques can be used to treat MPS, pharmacological treatment is the primary therapy for pain relief. However, given the chronic course of pain in patients with MPS, non-pharmacological approaches are also important for reducing medication dosages and the risk of adverse reactions. Several studies have indicated that relaxing techniques such as progressive muscle relaxation ${ }^{7,8)}$, massage ${ }^{9)}$, and meditation ${ }^{10)}$ can aid in relieving pain. Additional evidence suggests that biofeedback training can induce relaxation and decrease pain ${ }^{11-13)}$.

*Corresponding author. Vorasith Siripornpanich (E-mail: vorasith.sir@gmail.com)

(C2020 The Society of Physical Therapy Science. Published by IPEC Inc.

(c) (i) $\odot$ This is an open-access article distributed under the terms of the Creative Commons Attribution Non-Commercial No Deriva-

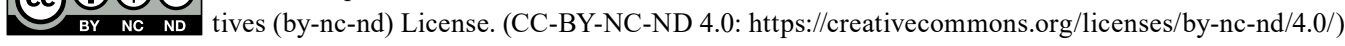


Electromyography (EMG) biofeedback training has been used to relieve muscle tension and increase muscle strength ${ }^{14,15)}$. In such training, electrical signals are detected during muscle contraction, and the patient is provided with auditory or visual feedback $^{15,16)}$. Electromyography biofeedback has been used to reduce muscle tension ${ }^{15}$, increase muscle strength in patients with spinal cord injury ${ }^{14)}$, improve urinary incontinence in children ${ }^{17}$ ), and increase muscle power in patients with hemiplegia ${ }^{18,19)}$. Nevertheless, such studies have typically focused on motor functions (e.g., muscle power/tension), while relatively few have evaluated the effects of EMG biofeedback on the brain, particularly on neural activity and pain reduction $^{20,21)}$. Therefore, in the present study, neural activity in patients with MPS during EMG biofeedback training designed to induce muscle relaxation was aimed to investigate. The duration of efficacy for EMG biofeedback training and pain perception after treatment in patients with MPS were also examined. To the best of our knowledge, this is the first study to evaluate both brain activity and pain perception after EMG biofeedback in patients with MPS.

\section{PARTICIPANTS AND METHODS}

This study included 27 participants (4 males and 23 females) with MPS in the upper trapezius ${ }^{22)}$. All participants met the following inclusion criteria: age between 20-40 years old, right-handed as assessed using the Edinburgh Handedness Inventory ${ }^{23}$, and mild-to-moderate levels of pain (score $\left.<7.4\right)^{24)}$. Exclusion criteria were as follows: history of neurological/ psychiatric disorders, history of substance abuse, history of head injury, current treatment with CNS-active medications. All experimental procedures were approved by the Mahidol University Central Institutional Review Board (COA No. MU-CIRB 2018/121.2106). All participants provided written informed consent prior to the experiment.

For the EMG biofeedback session, surface electrodes (Myotrace 400, Noraxon INC., USA) were placed over both upper trapezius muscles, while a single ground surface electrode was placed over the styloid process of the ulna. The EMG biofeedback was conducted by a physical therapist (N.K.) for all participants. A loud sound was played when the EMG signal was higher than the threshold level due to muscle contraction. Participants were instructed to reduce the volume of the sound by relaxing their muscles. When the sound level had decreased, the examiner reduced the threshold to make the task more difficult. Participants were instructed to continuously perform sound-reduction procedure until the end of the experiment.

Prior to the experiment, participants were requested to provide a pain score, following which they remained seated in a comfortable chair in a relaxed position throughout the electroencephalography (EEG) recording period. The EEG was recorded during daytime either morning or afternoon sessions. The number of participants in each session was approximately equal. During EEG recording, participants were instructed to close their eyes for $5 \mathrm{~min}$ to assess baseline neural activity. EMG electrodes were then applied over both upper trapezius muscles, and participants were instructed to relax their muscles for $15 \mathrm{~min}$. EEG data were collected throughout the 15-min session. Immediately after the EMG biofeedback session, participants underwent additional EEG recording with their eyes closed for 5 minutes, following which they provided another pain rating. After another 10 min of rest in a comfortable chair, participants underwent EEG recording with their eyes closed for an additional $5 \mathrm{~min}$. All experimental procedures were shown in Fig. 1.

Pain levels were assessed using an algometer (JTECH Medical Industries, INC., USA). The examiner compressed the head of the algometer on the trigger points over both sides of the upper trapezius muscle with force of $25 \mathrm{~N}$. Participants were asked to rate their pain based on the Visual Analog Scale.

A 32-channel EEG cap was placed on each participant's head. Electrodes were placed in accordance with the international $10-20$ system $^{25}$. After applying the cap, EEG gel was applied to all electrodes to set the impedance to less than $5 \mathrm{k} \Omega$. Four electrodes were placed over both eyes, as well as the supraorbital and infraorbital region of the left eye, for the detection of eye movement. In addition, two reference electrodes were placed over each mastoid process. EEG data were recorded using Neuroscan version 4.3 (Compumedics Neuroscan, TX, USA), a bandpass filter of $0.1-60 \mathrm{~Hz}$, and A/D rate of $500 \mathrm{~Hz}$, and a notch filter of $50 \mathrm{~Hz}$.

Quantitative analysis was performed using fast Fourier transformation (FFT) to convert the raw EEG data into numerical data. The absolute power of brain activity was obtained across four frequency ranges: delta $(0.5-4 \mathrm{~Hz})$, theta $(4-8 \mathrm{~Hz})$, alpha

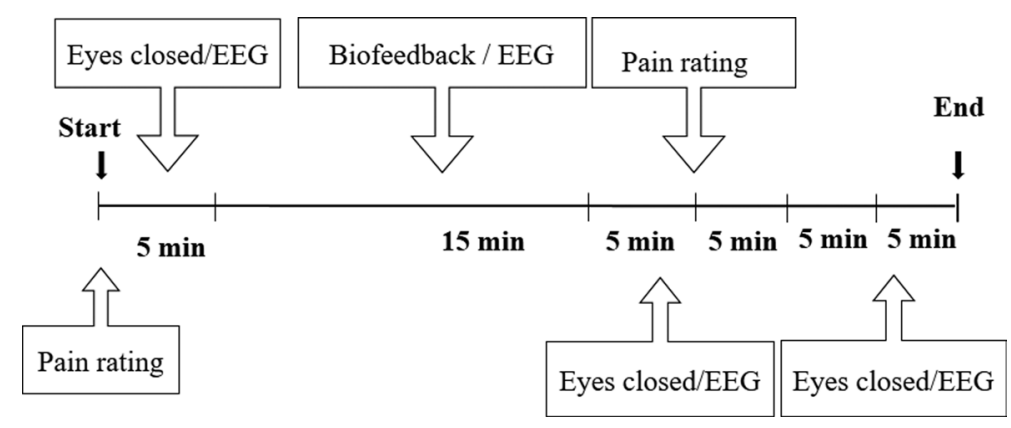

Fig. 1. The experimental procedure. 
$(8-13 \mathrm{~Hz})$, and beta $(13-30 \mathrm{~Hz})$. EEG data were first segmented to convert continuous signals into short segments of data (2,000 ms each). Artifact rejection was performed at $\pm 80 \mathrm{~Hz}$ and a bandpass filter of $0.3-30 \mathrm{~Hz}$. The first point of each EEG segment was used for baseline correction. Finally, the data were averaged in each frequency domain and presented as the absolute power $\left(\mu \mathrm{V}^{2}\right)$. The EEG data from adjacent electrodes were grouped together and presented for the following five brain areas: left anterior (Fp1, F3, and F7 electrodes), right anterior (Fp2, F4, and $\mathrm{F} 8$ electrodes), central (FCz, Cz, and CPz electrodes), left posterior (P3, T5, and $\mathrm{O} 1$ electrodes), and right posterior (P4, T6, and $\mathrm{O} 2$ electrodes) ${ }^{26)}$.

Data (mean \pm standard deviation) were analyzed using SPSS version 18 for Windows (SPSS Inc., IBM, USA). A-repeated measures analysis of variance (ANOVA) was used to analyze the absolute power of each brain frequency among the four experimental conditions. A paired t-test was used to compare pre- and post-intervention pain scores. The level of statistical significance was set to $\mathrm{p}<0.05$.

\section{RESULTS}

Quantitative EEG analysis revealed that delta power over the left posterior and central brain regions had significantly decreased after 15 min of EMG biofeedback training, when compared with that observed during the eyes-closed control condition $(\mathrm{p}<0.05)$ (Table 1 and Fig. 2).

Table 2 shows that alpha power significantly increased over the left anterior, right anterior, and central brain regions after

Table 1. Delta power over five cortical regions before, during, and after EMG biofeedback

\begin{tabular}{lcccc}
\hline \multirow{2}{*}{ Cortical regions } & \multicolumn{4}{c}{ Delta power $\left(\mu \mathrm{V}^{2}\right)$} \\
\cline { 2 - 5 } & $\mathrm{EC}$ & $\mathrm{BF}$ & $\mathrm{AFT} 0 \mathrm{~min}$ & AFT 15 min \\
\hline Left anterior & $14.53 \pm 5.56$ & $13.49 \pm 5.11$ & $13.53 \pm 4.83$ & $15.06 \pm 7.45$ \\
Right anterior & $14.79 \pm 6.42$ & $14.08 \pm 5.53$ & $14.12 \pm 5.57$ & $15.65 \pm 8.74$ \\
Left posterior & $7.58 \pm 4.1^{*}$ & $6.37 \pm 2.69$ & $6.3 \pm 2.98$ & $5.76 \pm 2.72^{*}$ \\
Right posterior & $6.92 \pm 2.8$ & $6.34 \pm 2.48$ & $6.37 \pm 2.89$ & $5.95 \pm 2.66$ \\
Central & $12.79 \pm 4.63^{*}$ & $11.73 \pm 4.06$ & $12.26 \pm 5.71$ & $10.3 \pm 3.37^{*}$ \\
\hline
\end{tabular}

*Significant difference between EC and AFT 15 min, $\mathrm{p}<0.05$.

EC: eyes-closed condition; BF: EMG biofeedback; AFT 0 min: immediately after EMG biofeedback (at 0 min); AFT 15 min: 15 min after EMG biofeedback.

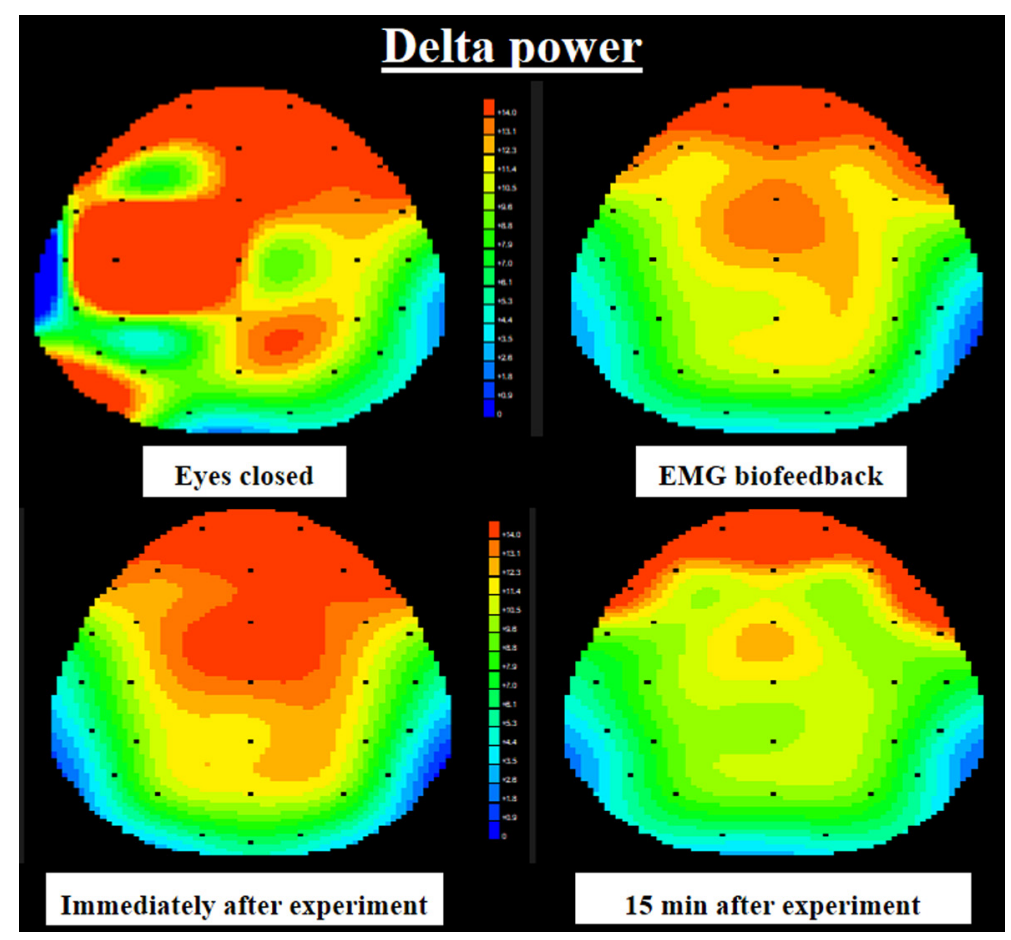

Fig. 2. Topographic brain map of delta power during the eyes-closed period, the EMG biofeedback period, immediately after training, and 15 minutes after training. 
15 min of EMG biofeedback training, when compared with that observed during the eyes-closed control condition ( $\mathrm{p}<0.05$ ). Increases in alpha power were also observed over the left posterior, right posterior, and central brain regions when training and post-training EEG signals (15 min) were compared ( $\mathrm{p}<0.05)$ (Fig. 3).

In contrast, there were no significant differences in theta or beta power among the eyes closed, training, immediate posttraining, and 15-min post-training conditions.

Despite a trend towards decreasing scores for both trapezius muscles, no significant differences between pre-training and post-training pain scores were observed (Table 3).

Table 2. Alpha power over five cortical regions before, during, and after EMG biofeedback

\begin{tabular}{lcccc}
\hline \multirow{2}{*}{ Cortical regions } & \multicolumn{4}{c}{ Alpha power $\left(\mu \mathrm{V}^{2}\right)$} \\
\cline { 2 - 5 } & $\mathrm{EC}$ & $\mathrm{BF}$ & $\mathrm{AFT} 0 \mathrm{~min}$ & AFT 15 min \\
\hline Left anterior & $3.13 \pm 2.1^{*}$ & $5.16 \pm 4.17$ & $5.69 \pm 6.13$ & $7.64 \pm 5.91^{*}$ \\
Right anterior & $3.34 \pm 2.2^{*}$ & $5.54 \pm 4.53$ & $6.13 \pm 6.75$ & $8.14 \pm 6.29^{*}$ \\
Left posterior & $5.74 \pm 5.81$ & $4.29 \pm 5.09^{* *}$ & $6.25 \pm 6.87$ & $8.83 \pm 7.63^{* *}$ \\
Right posterior & $5.8 \pm 5.13$ & $3.92 \pm 3.99^{* *}$ & $6.31 \pm 6.42$ & $8.79 \pm 6.61^{* *}$ \\
Central & $7.37 \pm 5.59^{*}$ & $5.02 \pm 4.17^{* *}$ & $8.06 \pm 7.77$ & $11.1 \pm 7.77^{* * *}$ \\
\hline
\end{tabular}

*Significant difference between EC and AFT 15 min, $\mathrm{p}<0.05$.

$* *$ Significant difference between BF and AFT $15 \mathrm{~min}, \mathrm{p}<0.05$

EC: eyes-closed condition; BF: EMG biofeedback; AFT 0 min: immediately after EMG biofeedback (at 0 min); AFT 15 min: 15 min after EMG biofeedback.

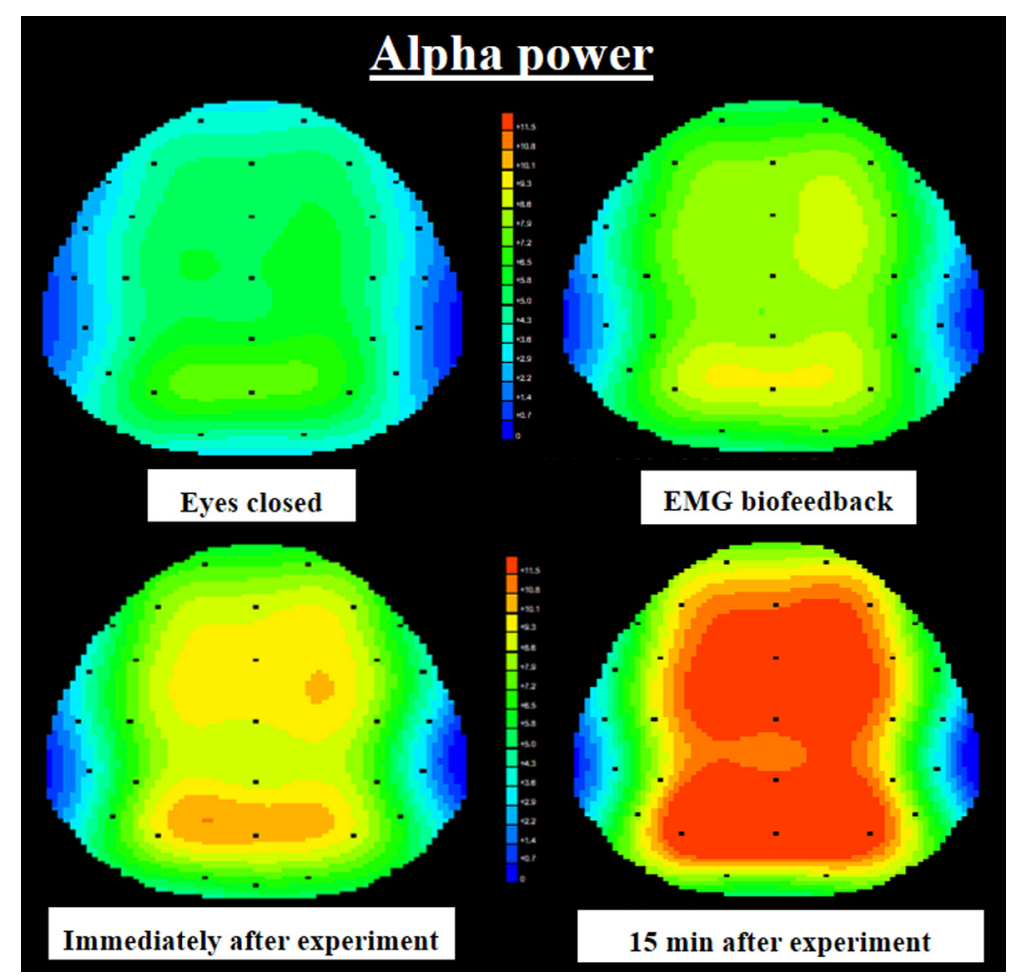

Fig. 3. Topographic brain map of alpha power during the eyes-closed period, the EMG biofeedback period, immediately after training, and 15 min after training.

Table 3. Pain scores before and after EMG biofeedback

\begin{tabular}{lcc}
\hline \multirow{2}{*}{ Side } & \multicolumn{2}{c}{ Pain score } \\
\cline { 2 - 3 } & Before & After \\
\hline Left shoulder & $3.82 \pm 2.01$ & $3.34 \pm 2.15$ \\
Right shoulder & $3.82 \pm 2.01$ & $3.38 \pm 2.18$ \\
\hline
\end{tabular}




\section{DISCUSSION}

Although several previous studies have examined the effect of EMG biofeedback on muscle tension, the present study is the first to utilize EEG to investigate the effects of EMG biofeedback training on neural activity and pain perception in patients with MPS of the upper trapezius muscle, as well as the duration of these effects. Our results demonstrated that EMG biofeedback training decreased delta power and increased alpha power over all brain regions at 15 min after training. In general, delta waves are most commonly associated with deep sleep ${ }^{27)}$, while alpha waves are most commonly associated with an eyes-closed, relaxed waking state ${ }^{27,28)}$. Therefore, our findings suggest that EMG biofeedback training induced relaxation in awake patients with MPS. Significant changes in EEG signals were observed 15 min post-training but not during the experimental session, indicating that training-induced relaxation can only be detected following the session. This may be due to arousal/anxiety induced by the auditory stimulus during training ${ }^{29-31)}$. Previous studies have also reported that biofeedback can promote relaxation in students experiencing stress via reductions in heart rate, suggesting that biofeedback training can regulate emotion ${ }^{8}$. Masafi et al. demonstrated that skin conductance biofeedback can decrease state anxiety scores in patients with cancer receiving chemotherapy ${ }^{13}$. Moreover, another study indicated that biofeedback-assisted relaxation breathing and progressive muscle relaxation techniques can reduce stress scores in patients with asthma ${ }^{32}$.

Although there was a tendency for scores to decrease, no significant decreases in pain scores were observed following EMG biofeedback training in our study. Ma et al. revealed that EMG biofeedback can reduce pain over the neck and shoulder areas in individuals engaged in computer work, suggesting that the training may aid participants in learning to control muscle tension. Indeed, a previous study reported that adjusting motor control during biofeedback can help to relax neck and shoulder muscles, thereby leading to decreases in pain perception ${ }^{33)}$. The lack of a significant decrease in pain perception in the current study may be explained by the short duration of EMG biofeedback training (15 min). In general, biofeedback training is usually conducted for at least 4 weeks ${ }^{14,34)}$. Therefore, it is possible that short-term EMG biofeedback training alters brain activity without apparent decreases in muscle tension. Furthermore, pain scores as assessed using the VAS are highly subjective ${ }^{35}$ ), which may also explain our non-significant result.

The present study possesses some limitations of note, including the subjective nature of our pain assessments, and the absence of a control group. Further study in long-term EMG biofeedback training is recommended to clarify the effect of EMG biofeedback on pain in patients with MPS. Despite these limitations, our results demonstrate that short-term EMG biofeedback training exerts a relaxing effect in patients with MPS of the upper trapezius muscle, based on the observed increases in alpha power and decreases in delta power at 15 -min post-training.

\section{Funding}

Funding was provided by Rangsit University, Pathumthani, Thailand.

\section{Conflict of interest}

The authors declare no conflicts of interest.

\section{ACKNOWLEDGMENTS}

The authors would like to thank all participants for their great cooperation. We also thank Asst. Prof. Sukonthar Ngampramuan for her technical assistance during the study. Authors would like to thank Editage (www.editage.com) for English language editing. Finally, we also wish to thank our colleagues for their assistance throughout the experiment.

\section{REFERENCES}

1) McBeth J, Jones K: Epidemiology of chronic musculoskeletal pain. Best Pract Res Clin Rheumatol, 2007, 21: 403-425. [Medline] [CrossRef]

2) de Souza JB, Grossmann E, Perissinotti DM, et al.: Prevalence of chronic pain, treatments, perception, and interference on life activities: Brazilian populationbased survey. Pain Res Manag, 2017, 2017: 4643830. [Medline] [CrossRef]

3) Giamberardino MA, Affaitati G, Fabrizio A, et al.: Myofascial pain syndromes and their evaluation. Best Pract Res Clin Rheumatol, 2011, 25: 185-198. [Medline] [CrossRef]

4) Borg-Stein J, Iaccarino MA: Myofascial pain syndrome treatments. Phys Med Rehabil Clin N Am, 2014, 25: 357-374. [Medline] [CrossRef]

5) Gerwin RD: Diagnosis of myofascial pain syndrome. Phys Med Rehabil Clin N Am, 2014, 25: 341-355. [Medline] [CrossRef]

6) Cerezo-Téllez E, Torres-Lacomba M, Mayoral-Del Moral O, et al.: Prevalence of myofascial pain syndrome in chronic non-specific neck pain: a populationbased cross-sectional descriptive study. Pain Med, 2016, 17: 2369-2377. [Medline] [CrossRef]

7) de Paula AA, de Carvalho EC, dos Santos CB: The use of the "progressive muscle relaxation" technique for pain relief in gynecology and obstetrics. Rev Lat Am Enfermagem, 2002, 10: 654-659. [Medline] [CrossRef]

8) Peciuliene I, Perminas A, Gustainiene L, et al.: Effectiveness of progressive muscle relaxation and biofeedback relaxation in lowering physiological arousal among students with regard to personality features. Procedia Soc Behav Sci, 2015, 205: 228-235. [CrossRef] 
9) Moraska AF, Schmiege SJ, Mann JD, et al.: Responsiveness of myofascial trigger points to single and multiple trigger point release massages: a randomized, placebo controlled trial. Am J Phys Med Rehabil, 2017, 96: 639-645. [Medline] [CrossRef]

10) Khan AA, Srivastava A, Passi D, et al.: Management of myofascial pain dysfunction syndrome with meditation and yoga: Healing through natural therapy Natl J Maxillofac Surg, 2018, 9: 155-159. [Medline] [CrossRef]

11) Anaraki F, Foroughifar T, Saba RB, et al.: Biofeedback therapy combined with diet to treating ODS (Anismus): 2 years outcome. J Coloproctol (Rio J), 2017, 37: 109-115. [CrossRef]

12) Jepson NA: Applications of biofeedback for patients with chronic pain. Tech Reg Anesth Pain Manage, 2008, 12: 111-114. [CrossRef]

13) Masafi S, Rezaei O, Ahadi H: Efficacy of biofeedback associated with relaxation in decreasing anxiety in women with breast cancer during chemotherapy. Procedia Soc Behav Sci, 2011, 30: 143-148. [CrossRef]

14) De Biase ME, Politti F, Palomari ET, et al.: Increased EMG response following electromyographic biofeedback treatment of rectus femoris muscle after spinal cord injury. Physiotherapy, 2011, 97: 175-179. [Medline] [CrossRef]

15) Peck CL, Kraft GH: Electromyographic biofeedback for pain related to muscle tension. A study of tension headache, back, and jaw pain. Arch Surg, 1977, 112: 889-895. [Medline] [CrossRef]

16) Herrington L: EMG biofeedback: what can it actually show? Physiotherapy, 1996, 82: 581-583. [CrossRef]

17) Ebiloglu T, Kaya E, Köprü B, et al.: Biofeedback as a first-line treatment for overactive bladder syndrome refractory to standard urotherapy in children. J Pediatr Urol, 2016, 12: 290.e1-290.e7. [Medline] [CrossRef]

18) Del Din S, Bertoldo A, Sawacha Z, et al.: Assessment of biofeedback rehabilitation in post-stroke patients combining fMRI and gait analysis: a case study. J Neuroeng Rehabil, 2014, 11: 53. [Medline] [CrossRef]

19) Stanton R, Ada L, Dean CM, et al.: Biofeedback improves performance in lower limb activities more than usual therapy in people following stroke: a systematic review. J Physiother, 2017, 63: 11-16. [Medline] [CrossRef]

20) Barth B, Mayer K, Strehl U, et al.: EMG biofeedback training in adult attention-deficit/hyperactivity disorder: an active (control) training? Behav Brain Res, 2017, 329: 58-66. [Medline] [CrossRef]

21) Criado L, de La Fuente A, Heredia M, et al.: Electromyographic biofeedback training for reducing muscle pain and tension on masseter and temporal muscles: A pilot study. J Clin Exp Dent, 2016, 8: e571-e576. [Medline]

22) Simons DG, Travell JG, Simons LS: The trigger point manual. 2nd ed. Baltimore: Williams \& Wilkins, 1999.

23) Oldfield RC: The assessment and analysis of handedness: the Edinburgh inventory. Neuropsychologia, 1971, 9: 97-113. [Medline] [CrossRef]

24) Boonstra AM, Schiphorst Preuper HR, Reneman MF, et al.: Reliability and validity of the visual analogue scale for disability in patients with chronic musculoskeletal pain. Int J Rehabil Res, 2008, 31: 165-169. [Medline] [CrossRef]

25) Jasper HH: The ten-twenty electrode system of the international federation. Electroencephalogr Clin Neurophysiol, 1958, 10: 371-375.

26) Sayorwan W, Siripornpanich V, Piriyapunyaporn T, et al.: The effects of lavender oil inhalation on emotional states, autonomic nervous system, and brain electrical activity. J Med Assoc Thai, 2012, 95: 598-606. [Medline]

27) Constant I, Sabourdin N: The EEG signal: a window on the cortical brain activity. Paediatr Anaesth, 2012, 22: 539-552. [Medline] [CrossRef]

28) Teplan M: Fundamentals of EEG measurement. Meas Sci Rev, 2002, 2: 1-11.

29) Beutel ME, Jünger C, Klein EM, et al.: Noise annoyance is associated with depression and anxiety in the general population-the contribution of aircraft noise PLoS One, 2016, 11: e0155357. [Medline] [CrossRef]

30) Münzel T, Gori T, Babisch W, et al.: Cardiovascular effects of environmental noise exposure. Eur Heart J, 2014, 35: 829-836. [Medline] [CrossRef]

31) Westman JC, Walters JR: Noise and stress: a comprehensive approach. Environ Health Perspect, 1981, 41: 291-309. [Medline] [CrossRef]

32) Georga G, Chrousos G, Artemiadis A, et al.: The effect of stress management incorporating progressive muscle relaxation and biofeedback-assisted relaxation breathing on patients with asthma: a randomised controlled trial. Adv Integr Med, 2019, 6: 73-77. [CrossRef]

33) Ma C, Szeto GP, Yan T, et al.: Comparing biofeedback with active exercise and passive treatment for the management of work-related neck and shoulder pain: a randomized controlled trial. Arch Phys Med Rehabil, 2011, 92: 849-858. [Medline] [CrossRef]

34) Cox DJ, Freundlich A, Meyer RG: Differential effectiveness of electromyograph feedback, verbal relaxation instructions, and medication placebo with tension headaches. J Consult Clin Psychol, 1975, 43: 892-898. [Medline] [CrossRef]

35) Soltani R, Soheilipour S, Hajhashemi V, et al.: Evaluation of the effect of aromatherapy with lavender essential oil on post-tonsillectomy pain in pediatric patients: a randomized controlled trial. Int J Pediatr Otorhinolaryngol, 2013, 77: 1579-1581. [Medline] [CrossRef] 